\title{
Haemopneumothorax from congenital cystic adenomatoid malformation in a cryptorchidism patient
}

\author{
S-C. Lee*, Y-L. Cheng*, C-P. Yu**
}

\begin{abstract}
Haemopneumothorax from congenital cystic adenomatoid malformation in a cryptorchidism patient. S-C. Lee, Y-L. Cheng, C-P. Yu. C)ERS Journals Ltd 2000.

ABSTRACT: Congenital cystic adenomatoid malformation (CCAM) of the lung is an uncommon congenital anomaly, especially in young adults. This study reports an 18yr-old male with CCAM involving the right upper lobe, who presented with a moderate spontaneous haemopneumothorax initially. The patient also had bilateral abdominal cryptorchidism which required surgical treatment earlier in childhood. The chest radiographs and contrast-enhanced computed tomographic scan of the chest showed a multicystic lesion with air-fluid levels in the right upper lung. The right upper lobe was resected through a posterolateral thoracotomy. Histological examination confirmed the diagnosis of CCAM.

To the authors' knowledge, congenital cystic adenomatoid malformation presenting with spontaneous haemopneumothorax and haemoptysis has never been described in the literature.
\end{abstract}

Eur Respir J 2000; 15: 430-432.
*Division of Thoracic Surgery, Dept of Surgery, and **Dept of Pathology, TriService General Hospital, National Defense Medical Center, Taipei, Taiwan.

Correspondence: S-C. Lee, Division of Thoracic Surgery, Dept of Surgery, TriService General Hospital, 8 Ting-Chou Road, Section 3, Taipei, 100, Taiwan. Fax: 886223680995

Keywords: Congenital cystic adenomatoid malformation, cryptorchidism,

haemoptysis, haemothorax, lobectomy, pneumothorax

Received: January 121999

Accepted after revision June 291999
Congenital cystic adenomatoid malformation (CCAM) is a rare congenital anomaly. It was well described by CH'IN and TANG [1] in 1949 and characterized by the adenomatous overgrowth of the terminal bronchioles, with formation of cystic space-occupying lesion [1-3]. Spontaneous pneumothorax is a rare presentation of CCAM in children [4], but to the authors' knowledge, haemopneumothorax and haemoptysis due to CCAM have never been reported. Cryptorchidism has also never been described in association with CCAM. This report describes a young male with cryptorchidism and a congenital cystic lesion of the lung presenting with spontaneous haemopneumothorax.

\section{Case report}

The patient was an 18-yr-old male, presenting to the Emergency Department of the authors hospital with a 4-day history of chest pain followed by progressive dyspnoea. He was born by spontaneous delivery to a 30yr-old mother after a normal 38 weeks' gestation. He had a history of bilateral undescending testes since birth. Abdominal cryptorchid testes were diagnosed by a laparoscopic approach when he was 6 yrs old. Right orchiectomy, due to atrophy of right testis, and left orchioplexy, due to hypotrophy of left testis, were performed later. He developed well and had no previous respiratory problems. There was no history of major trauma, tobacco or alcohol abuse. There was also no history of atopy or a familial history of respiratory disease.

On physical examination, he appeared well. His height was $162 \mathrm{~cm}$ and weight $48 \mathrm{~kg}$. His temperature was $36.8^{\circ} \mathrm{C}$, pulse 84 beats $\cdot \min ^{-1}$, respiration rate 18 breaths $\cdot \min ^{-1}$ and blood pressure $110 / 70 \mathrm{mmHg}$. There was symmetrical chest wall movement. Breath sounds were diminished over the right hemithorax. There were several old surgical scars over his abdominal wall and inguinal region. Absence of right testis and a small testis in the left sac of the scrotum were found. Initial chest radiograph showed right massive pneumothorax with total collapse of the right lung, contralateral mediastinal shift and obliteration of the right costophrenic angle. A chest tube was inserted and $50 \mathrm{~mL}^{-1}$ of fresh blood drained out initially. A repeated chest film showed that the right lung had reexpanded, but a multicystic lesion with air-fluid levels in the right upper lung was seen. Laboratory studies revealed a haematocrit level of $42.8 \%$, a white blood cell (WBC) count of 10,500 cells $\cdot \mathrm{mL}^{-1}$. The platelet count, prothrombin time (PT), and partial thromboplastin time (PTT) were normal. On admission, he appeared comfortable while breathing 30\% oxygen by nasal cannulae. Two hours later, he developed haemoptysis $(50 \mathrm{~mL})$ and fresh blood drained from the chest tube. Cold sweating, palpitations and dizziness developed later. The pulse was 120 beats $\mathrm{min}^{-1}$, respiration rate 20 breaths $\cdot \mathrm{min}^{-1}$, and the blood pressure $90 / 60 \mathrm{mmHg}$. The chest tube drained $150 \mathrm{~mL}$ of blood over $30 \mathrm{~min}$. The haematocrit dropped to $36.4 \%$. His vital signs stabilized after intravenous resuscitation with $1,000 \mathrm{~mL}$ Ringer's solution and $500 \mathrm{~mL}$ packed red blood cells. The subsequent chest radiograph showed right haemopneumothorax and a multicystic lesion with air-fluid levels in the right hilar area (fig. 1). The haemoptysis stopped and the total amount of blood drained by the chest tube was $200 \mathrm{~mL}$ in $12 \mathrm{~h}$. A contrast-enhanced computed tomographic (CT) scan of the chest showed a right haemopneumothorax and 


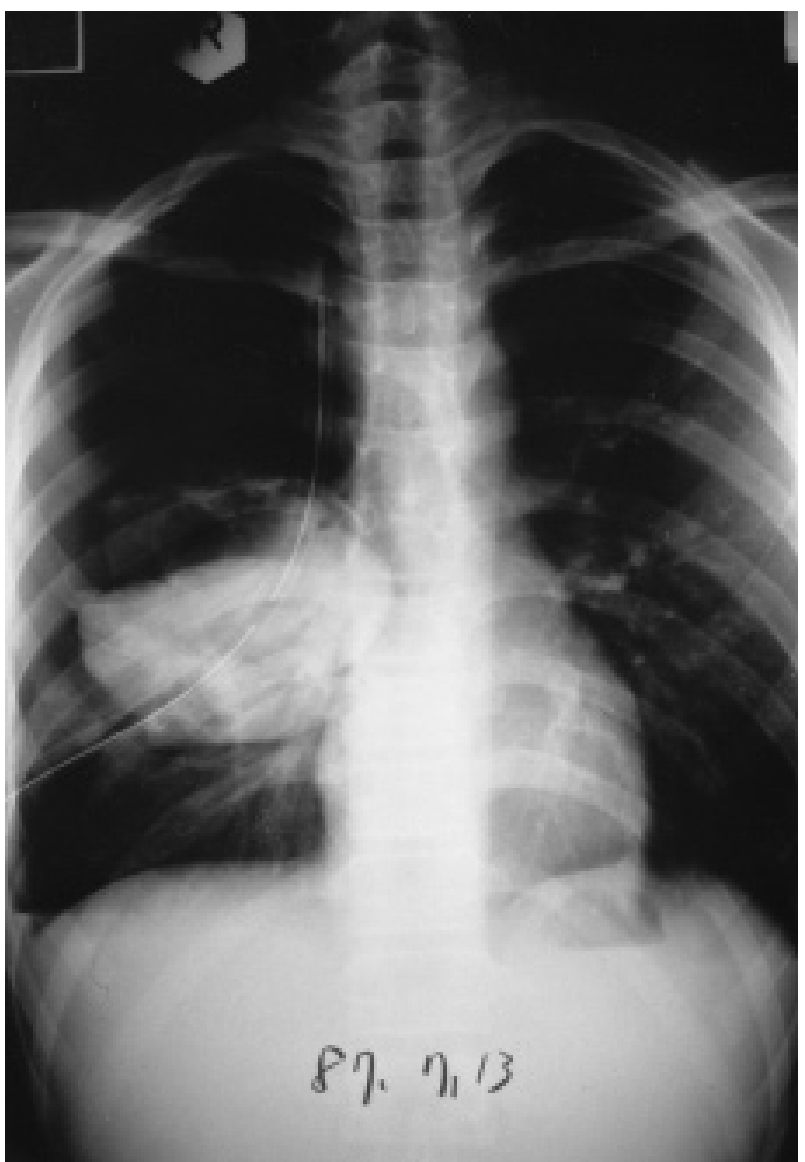

Fig. 1. - Chest roentgenogram, antero-posterior view, showing a large multiloculated cystic lesion with air-fluid level occupying the right lung an haemopneumothorax in the right hemithorax.

a multiloculated cystic lesion in the right upper lung with multiple air-fluid levels. Chromosomal studies revealed no abnormalities.

The clinical and radiological pictures supported the diagnosis of a congenital cystic lesion. At thoracotomy, the right upper lobe contained a multiloculated cystic lesion. A right upper lobectomy was performed. Grossly, the resected lesion was $10 \times 8 \times 5 \mathrm{~cm}$, purple in colour, and was comprised of multiple cysts up to $5 \times 4 \times 3 \mathrm{~cm}$ (fig. 2 ). The lesion was filled with $500 \mathrm{~mL}$ dark blood and clots. Histological examination showed that multiple cystic air spaces were separated by septa and lined by nonciliated, respiratory-like columnar epithelium (fig. 3). It was compatible with type 1 CCAM [2]. Within the cysts, there were collections of red blood cells, haemosiderin, and macrophages. The patient had an uneventful postoperative course.

\section{Discussion}

CCAM of the lung is a rare form of lung disease, but accounts for $25 \%$ of congenital lung diseases. It has mostly been diagnosed in newborn infants presenting with respiratory distress secondary to the expanding cysts compressing the surrounding structure $[2,5]$. This disorder has also been reported in older children but is rare in adults. In

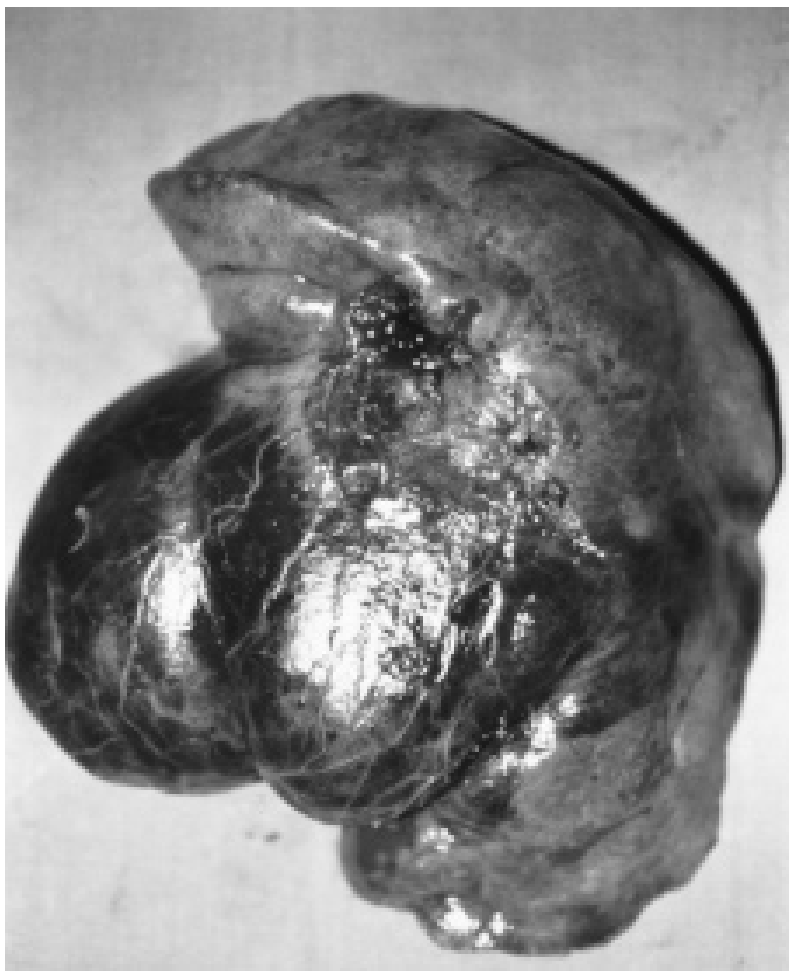

Fig. 2. - Gross appearance of the resected lung specimen demonstrating a multicystic lesion with blood content, measuring $10 \times 8 \times 5 \mathrm{~cm}$. Scale bar $=2 \mathrm{~cm}$.

adults, CCAM should be differentiated from other cystic diseases including bullous disease, cavitating lung infection, post-inflammatory pneumatoceles, bronchogenic cysts, pulmonary sequestration and bronchopulmonaryforgut anomalies $[6,7]$. The diagnosis is suggested from the clinical presentations and imaging characteristics, but can be confirmed only by histopathological findings. The following histological criteria for CCAM, described by MiLLER et al. [8], have been generally accepted as: 1) varying sized cysts, lined by cuboidal to columnar epithelium; 2) polypoid configuration of the mucosa of the cysts; 3) absence of cartilage; 4) presence of a group of mucogenic cells lining the cyst wall; and 5) absence of inflammation.

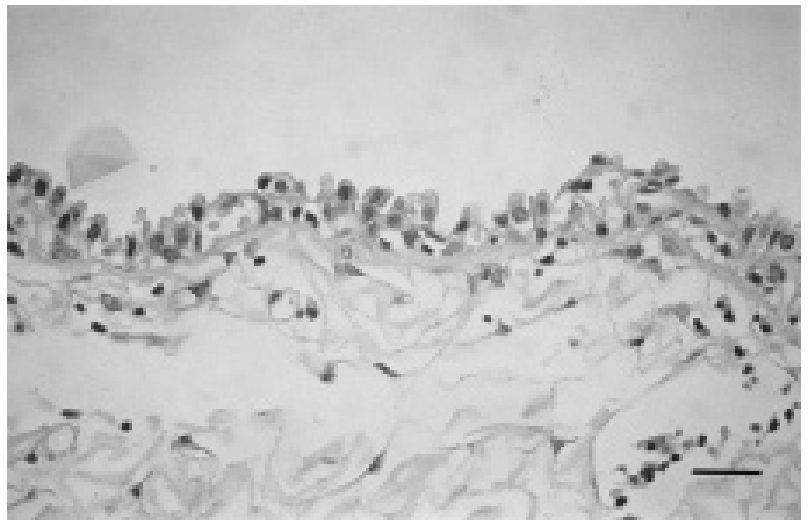

Fig. 3. - Photomicrograph of the resected lung mass showing cysts lined by pseudostratified columnar epithelium. (Haematoxylin and eosin stain, internal scale bar $=25 \mu \mathrm{m}$.) 
A spontaneous pneumothorax is a rare clinical presentation in CCAM. [9] To the authors' knowledge, CCAM associated with spontaneous haemopneumothorax and haemoptysis has never been reported in the literature. The presentation of haemopneumothorax and haemoptysis were felt to be due to a tear of the vessels in the lesion leading to fresh bleeding into the pleural cavity and tracheobronchial tree. Urgent surgical treatment should be performed if massive haemothorax or haemoptysis occur. Careful identification and ligation of the aberrant vessels associated with the congenital lesion during surgery should be performed to avoid uncontrolled bleeding and mortality.

Congenital cystic adenomatoid malformation can be associated with other congenital malformations, including anasarca, renal agenesis, Potter's syndrome, pectus excavatum or bile duct hypoplasia $[10,11]$. Congenital cystic adenomatoid malformation association with cryptorhid testes has never, to the authors' knowledge been described in the literature. Whether this is a fortuitous association or not remains to be determined.

\section{References}

1. Ch'in KY, Tang MY. Congenital cystic adenomatoid malformation of one lobe of a lung with general anasarca. Arch Pathol Lab Med 1949; 48: 221-229.

2. Stocker JT, Madewell JE, Drake RM. Congenital cys- tic adenomatoid malformation of the lung; classification and morphologic spectrum. Hum Pathol 1977; 8: 155171.

3. Kravitz RM. Congenital malformations of the lung. Pediatr Clin North Am 1994; 41: 453-472.

4. Heij HA, Ekkelkamp S, Vos A. Diagnosis of congenital cystic adenomatoid malformation of the lung in newborn infants and children. Thorax 1990; 45: 122-125.

5. Walker J, Cudmore RE. Respiratory problems and cystic adenomatoid malformation of lung. Arch Dis Child 1990; 65: 649-650.

6. Plit ML, Blott JA, Lakis N, Murray J, Plit M. Clinical, radiographic and lung function features of diffuse congenital cystic adenomatoid malformation of the lung in an adult. Eur Respir J 1997; 10: 1680-1682.

7. Hulnick DH, Naidich DP, McCauley DI, et al. Late presentation of congenital cystic adenomatoid malformation of the lung. Radiology 1984; 151: 569-573.

8. Miller RK, Sieber WK, Yunis EJ. Congenital adenomatoid malformation of the lung. Pathol Annu 180; 15: 387406.

9. Bentur L, Canny G, Thorner P, Superina R, Babyn P, Levison H. Spontaneous pneumothorax in cystic adenomatoid malformation: unusual clinical and histologic features. Chest 1991; 5: 1292-1293.

10. Cloutier MM, Schaeffer DA, Hight D. Congenital cystic adenomatoid malformation. Chest 1993; 103: 761-764.

11. Garcia H, Heidi G, Stöhr G. Congenital cystic adenomatoid malformation of the lung associated with bile duct hypoplasia. Path Res Pract 1988; 183: 71-77. 